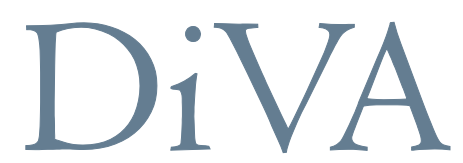

http://uu.diva-portal.org

This is an author produced version of a paper published in Ecological Entomology. This paper has been peer-reviewed but does not include the final publisher proof-corrections or journal pagination.

Citation for the published paper:

Abbott, Jessica K.; Gosden, Thomas P.

"Correlated morphological and colour differences among females of the damselfly Ischnura elegans"

Ecological Entomology, 2009, Vol. 34, Issue 3, pp. 378-386

http://dx.doi.org/10.1111/i.1365-2311.2009.01087.x

The definitive version is available at www.blackwell-synergy.com. Access to the definitive version may require subscription. 


\section{Correlated morphological and colour differences among females of the}

damselfly Ischnura elegans

J. K. Abbott* and T. P. Gosden

Department of Animal Ecology

Ecology Building

Lund University

SE-223 63 Lund, Sweden

*Author for correspondence: abbottj@queensu.ca

Current address:

Department of Biology

Queen's University

Kingston, Ont.

Canada K7L 3N6

Phone: 613-533-6000 x77566

Fax: 613-533-6617

Running head: Morphological differences in I. elegans

Keywords: size, shape, sexual dimorphism, polymorphism, selection, phenotypic integration 


\section{ABSTRACT}

1 1. The female-limited colour polymorphic damselfly Ischnura elegans has proven to be an

2 interesting study organism both as an example of female sexual polymorphism, and in the

3 context of the evolution of colour polymorphism. The study of colour polymorphism can also

4 have broader applications as a model of speciation processes.

5

6 2. Previous research suggests that there exist correlations between colour morph and other

7 phenotypic traits, and that the different female morphs in I. elegans may be pursuing

8 alternative phenotypically integrated strategies. However, previous research on morphological

9 differences in southern Swedish individuals of this species was only carried out on laboratory-

10 raised offspring from a single population, leaving open the question of how widespread such

11 differences are.

13 3. We therefore analysed multi-generational data from 12 populations, investigating

14 morphological differences between the female morphs in the field, differences in the pattern

15 of phenotypic integration between morphs, and quantified selection on morphological traits.

17 4. We found that consistent morphological differences did indeed exist between the morphs

18 across all study populations, confirming that the previously observed differences were not

19 simply a laboratory artefact. We also found, somewhat surprisingly, that despite the existence

20 of sexual dimorphism in body size and shape, patterns of phenotypic integration differed most

21 between the morphs and not between the sexes. Finally, linear selection gradients showed that

22 female morphology affected fecundity differently between the morphs. 
245 . We discuss the relevance of these results to the male mimicry hypothesis and to the 25 existence of potential ecological differences between the morphs. 
28 Adaptation to different ecological conditions is well-recognized as both a potential route to

29 speciation (Schluter, 2000; Nosil et al., 2003; Vines \& Schluter, 2006) and as the driver of the

30 evolution of polymorphism (Galeotti et al., 2003; Leimar, 2005; Ahnesjö \& Forsman, 2006).

31 Although ecological polymorphism is better studied to date, interest in sexual polymorphisms,

32 particularly female-limited sexual polymorphisms, is on the rise (reviewed in Svensson et al.,

33 in press). A recent review also highlighted the importance of studies of colour polymorphisms

34 as model systems of speciation processes (Gray \& McKinnon, 2007). An association between

35 differences in colour and differences in other traits seems to be a common feature in colour

36 polymorphic systems, and implies the existence of pleiotropic effects of colour on other traits

37 such as morphology or behaviour. For example, both male and female colour morphs in the

38 side-blotched lizard Uta stansburiana differ in aggression levels and in immune function

39 (Svensson et al., 2001; Mills et al., 2008). Similarly, colour morphs of the grasshopper Tetrix

40 undulata differ in body size even when reared under identical environmental conditions

41 (Ahnesjö \& Forsman, 2003).

43 The colour polymorphic damselfly Ischnura elegans has proven to be a useful study species

44 both in the context of colour polymorphisms in general and of specifically female-limited

45 sexual polymorphisms. The polymorphism in this species appears to be maintained, in part,

46 by negative frequency-dependent selection (Svensson et al., 2005) mediated by male mating

47 harassment (Gosden \& Svensson, 2007), and to be related to differences in morphology

48 (Abbott \& Svensson, 2008), development time (Abbott \& Svensson, 2005), and patterns of

49 intersexual genetic correlations (Abbott and Svensson, submitted), at least in the southern

50 Swedish populations studied in these papers. There also appear to be differences in behaviour 
51 between the morphs (Van Gossum et al., 2001a). An interesting twist to this story is the fact

52 that one of the female morphs is considered a male mimic (Robertson, 1985; Hinnekint, 1987;

53 Svensson et al., in press), and there is evidence both avoidance of male mimics by males

54 (Cordero et al., 1998; Hammers \& Van Gossum, 2008) which appears to be density-

55 dependent (Gosden and Svensson, submitted), and of learned mate recognition of common

56 morphs (Van Gossum et al., 2001b).

58 Although previous research has suggested that the female morphs in Ischnura elegans differ

59 in morphology (Abbott \& Svensson, 2008; Abbott and Svensson, submitted), these studies

60 were based on laboratory-raised individuals from a single population. We were also interested

61 in investigating whether male mimicry could affect selection on morphology and patterns of

62 phenotypic integration between female morphs. Here, we present results from a more

63 extensive analysis of multi-generational data from 12 populations, investigating

64 morphological differences between the morphs in the field. We found that consistent

65 morphological differences did indeed exist between the morphs across populations, that

66 morph-specific patterns of phenotypic integration existed between traits, and that fecundity

67 selection on these morphological traits differed between the morphs. We discuss the relevance

68 of these results to the male mimicry hypothesis and to potential ecological differences

69 between the morphs.

71 METHODS

72

73 Study species 
75 The blue-tailed damselfly, Ischnura elegans, is a small species with three female morphs and

76 monomorphic males (Corbet, 1999). I. elegans can be found in ponds set in open landscapes

77 across Europe from southern Sweden to northern Spain. This species is univoltine in Sweden,

78 although southern European populations are typically multivoltine (Askew, 1988). One of the

79 morphs, the Androchrome (A), has similar blue colouration and black melanin patterning as

80 males, and is considered a male mimic (Robertson, 1985; Hinnekint, 1987; Svensson et al., in

81 press). The Infuscans (I) morph is generally olive green when mature, but has the same black

82 melanin patterning as males and Androchromes. The third morph, Infuscans-obsoleta $(\mathrm{O})$, is

83 olive green to brown when mature and generally has less black colouration the other morphs,

84 including red (when immature) or brown (when mature) humeral stripes on the sides of the

85 thorax rather than black humeral stripes (for photographs and illustrations see Svensson et al., 86 in press).

88 The development of the female morphs of I. elegans is controlled by a single locus with three

89 alleles, similar to the closely related species, I. graellsii (Cordero, 1990; Sánchez-Guillén et 90 al., 2005). The three alleles form a dominance hierarchy, with the Androchrome allele (A)

91 dominant to the Infuscans (I) and Infuscans-obsoleta $(\mathrm{O})$ alleles and the I-allele dominant to 92 the O-allele (i.e. A > I > O, Sánchez-Guillén et al., 2005).

94 Data collection

96 We visited 12 populations outside Lund, in southern Sweden (Flyinge 30A1, Flyinge 30A3,

97 Genarp, Gunnesbo, Habo, Hofterupssjön, Höje å 14, Höje å 6, Höje å 7, Lomma, Vallby

98 mosse, and Vombs vattenverk) in the years 2002 to 2005. The geographic distance between

99 these populations ranges from 1.08 to $41.11 \mathrm{~km}($ mean $=14.54 \mathrm{~km})$. Our previous work 
100 examining molecular population differentiation using AFLP-markers has shown no evidence

101 of isolation by distance among these populations (Abbott, 2006). The average pairwise degree

102 of genetic differentiation $\left(\mathrm{F}_{\mathrm{st}}\right)$ between these populations is low to moderate and varies

103 between 0.016 and 0.051 (Abbott et al., 2008), indicating that these populations have

104 diverged genetically but are not completely independent. Several of these populations have

105 been relatively recently founded as part of a conservation program (Svensson \& Abbott,

106 2005) and are subject to frequent population extinctions and recolonizations (E. I. Svensson,

107 personal communication). These two factors possibly explain the observed increase in the

108 degree of neutral molecular population differentiation over the course of only two generations

109 (Abbott et al., 2008). These aspects of the genetic population structure of our study

110 populations suggest that these populations may not yet have reached their evolutionary

111 equilibria.

112

113 In each population damselflies were regularly collected over each season and five different

114 morphological measurements taken to the nearest $0.01 \mathrm{~mm}$ : total length, abdomen length,

115 thorax width, wing length, and width of the fourth segment of the abdomen (S4). Significant

116 narrow-sense heritabilities based on parent-offspring data have been found in four out of these

117 five traits (mean $h^{2}$ forewing length: 0.463 , total body length: 0.346 , abdomen length: 0.242 ,

118 thorax width: 0.173 ) when individuals have been raised in a common laboratory environment

119 (Abbott, 2006). The genetic correlations between the traits are positive in all cases (range:

$1200.025-1$ ) and are significant in 8 of the 10 cases (Abbott, 2006). A total of 4937 individuals

121 are included in the analysis of morphology, 2741 males and 2196 females (1457

122 Androchromes, 563 Infuscans, and 176 Infuscans-obsoleta). 
124 Fecundity data was collected as part of a long-term longitudinal investigation of our study

125 populations (Svensson et al., 2005; Svensson \& Abbott, 2005; Gosden \& Svensson, 2007;

126 Gosden \& Svensson, 2008; Gosden and Svensson, submitted). Field-caught females found in

127 copula were set up in plastic oviposition chambers in an indoor laboratory and left for two

128 days before being released. Eggs were counted on the third day. Sample sizes for the

129 fecundity data were as follows: 953 Androchromes, 515 Infuscans, and 129 Infuscans-

130 obsoleta. Our fecundity estimate is only a component of the total female lifetime fecundity,

131 and as such may or may not reflect actual differences in lifetime reproductive success.

132 However, it is known that fecundity from a single clutch can comprise $10-50 \%$ of the life-

133 time fecundity in female damselflies (Fincke, 1986; Banks \& Thompson, 1987; Corbet, 134 1999), and that inter-clutch intervals can be as short as one day (Banks \& Thompson, 1987).

135 A laying period of two days may therefore actually represent two clutches and is potentially a 136 good measure of fitness, especially since there is no evidence of morph-specific differences in

137 lifespan in this or in a closely related polymorphic species (Cordero, 1992; Cordero et al., 138 1998; Andrés \& Cordero Rivera, 2001). Our estimate is also likely to be a good fitness 139 component given that female damselflies will lay a large proportion of the eggs present in the 140 ovaries when presented with a favourable environment and left undisturbed (Corbet, 1999), 141 which is the case here.

143 Analysis

145 All analyses were carried out in STATISTICA (Statsoft, 2004). We first looked for evidence 146 of morphological differences between the sexes by carrying out a mixed-model MANOVA

147 with all 5 morphological measures as dependent variables, and Year (random effect), 148 Population (random effect), and Sex (fixed effect) as predictor variables (Population and Year 
149 were random effects since our dataset represents a subsample of all possible years and

150 populations, but the results do not change if they are instead treated as fixed effects). All two-

151 way interactions were included in the model. We also carried out an analysis of

152 morphological differences between the morphs using the same design, but with a fixed Morph

153 effect in place of the Sex effect (we could not include both Sex and Morph in the same

154 analysis since males are monomorphic). There was evidence of highly significant main effects

155 of both Sex and Morph (see Results), confirming our expectation of the existence of

156 morphological differences between these groups. In order to make these differences more

157 readily interpretable in terms of overall size and shape and to avoid any problems associated

158 with multicollinearity, we therefore performed a principal components analysis on all five

159 morphological measurements, and selected the first two PCs for further analysis using mixed

160 models of the same design as above.

161

162 Number of eggs laid was used in the calculation of linear selection gradients on all 5

163 morphological measures (Lande \& Arnold, 1983). Selection analysis was carried out in

164 several steps. First, morphological measures were standardized by female morph to a mean of

165 zero and standard deviation of 1 within each morph. Second, relative fecundity was calculated

166 separately for each morph. Standardized selection gradients were then estimated separately

167 for each morph using mixed models with fecundity values as the dependent variable, Year

168 and Population (and their interaction) as random effects to control for inter-population and

169 inter-year differences in fecundity, and each trait as fixed continuous factors. We then tested

170 for significant differences in the magnitude and/or direction of selection using a mixed model

171 with Year and Population (and their interaction) as random factors, each trait as fixed

172 continuous factors, and morph*trait interactions for each trait. In this analysis significant trait

173 effects indicate significant linear selection on that trait which is consistent across morphs, and 
174 significant trait*morph effects indicate that the magnitude and/or direction of selection on that

175 trait is dependent on female morph. Note that we did not include a main effect of Morph in

176 this analysis since fecundity values had already been standardized by female morph.

177 Quadratic selection gradients were also investigated, but were found to be non-significant in

178 all cases except one (there was some evidence of divergent selection on S4 width in

179 Androchromes) and are therefore not presented. Similarly, we looked for evidence of

180 variation in the strength and/or magnitude of selection between years and between

181 populations (c.f. Gosden \& Svensson, 2008) but found none (no significant year*trait or

182 population*trait interactions) so results from this analysis are not presented either.

184 Conditional independence graphs were constructed after Magwene (2001). This method

185 represents graphically the relationships between traits that remain after controlling for shared 186 correlations between traits. This is done by calculating the phenotypic correlation matrix for

187 the data set, inverting the matrix and then scaling the inverted matrix (Magwene, 2001),

188 which results in a matrix of partial correlations for the dataset. The matrix of partial

189 correlations is then tested for significance and strength of edges (Magwene, 2001) and

190 presented graphically. These conditional independence graphs are a convenient way of

191 visualizing phenotypic integration between traits (Magwene, 2001; Eroukhmanoff \&

192 Svensson, 2008). Similarity of phenotypic integration (partial correlation) matrices was

193 analysed using mantel tests, and differences in the magnitude of correlations between groups

194 were tested using t-tests. Although it would be interesting to see if differences in phenotypic

195 integration patterns between the sexes and the morphs are also dependent on year and

196 population, this would unfortunately result in very small sample sizes for some morph-year-

197 population combinations, leading to unreliable partial correlation estimates. We have instead 
198 elected to pool data from all years and populations and focus on general differences between

199 the sexes and the morphs.

\section{RESULTS}

203 Results from the MANOVA analyses indicated the existence of highly significant

204 morphological differences between the sexes $\left(\mathrm{F}_{5,4870}=1424.3, P<0.0001\right)$ and the morphs

$205\left(\mathrm{~F}_{10,4228}=11.0, P<0.0001\right)$. We therefore used PCA to obtain overall measures of size and

206 shape for further analysis. PC1 accounted for $63.98 \%$ of the total variation and was a measure

207 of overall size, since the factor loadings for all five traits were positive and large (Table 1).

208 PC2 accounted for $21.44 \%$ of the variation and had relatively high positive loadings on wing

209 length and abdomen width (S4) and high negative loadings on total length and abdomen

210 length (Table 1). This means that PC2 can be considered a measure of shape, and that

211 individuals with positive values of PC2 have relatively shorter, wider abdomens and longer

212 wings. This pattern of factor loadings for PC2 is qualitatively very similar to that found in a

213 previous laboratory analysis of morphology (Abbott \& Svensson, 2008), and suggests that

214 results for shape differences are comparable between these studies. All subsequent PCs

215 accounted for approximately $8 \%$ of the variation or less, and were therefore not analysed any

216 further.

218 Analysis of PC1 (body size) showed that differences between populations varied between 219 years (significant Population*Year effect, Table 2). Females were larger than males in all 220 populations (significant effect of Sex, Table 2A, LS means \pm SEs: females: $0.623 \pm 0.020$, 221 males: $-0.656 \pm 0.031$ ), but the degree of sexual size dimorphism varied between populations

222 (significant effect of Population*Sex, Table 2A, Figure 1A) and years (significant effect of 
223 Sex*Year, Table 2A, Figure 1B). Size differences between the female morphs trended toward

224 significance $(P<0.08$ Morph effect, Table 2B, Figure 2A), and there was no evidence of

225 variation in size dimorphism between populations or years (no significant effects of

226 Population*Morph or Morph*Year, Table 2B), in contrast to results for sexual size

227 dimorphism. Post-hoc tests showed that Infuscans females were significantly larger than

228 Androchrome and Infuscans-obsoleta females (Fig 2A, all $P<0.01$, LS means \pm SEs:

229 Androchromes: $0.613 \pm 0.027$, Infuscans: $0.718 \pm 0.046$, Infuscans-obsoleta: $0.578 \pm 0.070$ ).

231 Differences in PC2 (body shape) between populations were also dependent on year

232 (significant Population*Year effect, Table 3). There was sexual dimorphism in body shape 233 (PC2) in all populations (significant effect of Sex, Table 3A), and the difference between the

234 sexes was greater in some populations than in others (significant Population*Sex effect, Table 235 3A, Figure 1C), but there was no effect of year on sexual dimorphism in shape (no effect of 236 Year*Sex, Table 3A). Males had lower values of PC2 than females, in other words longer, 237 narrower abdomens and shorter wings than females (LS means \pm SEs: females: $0.711 \pm 0.021$, 238 males: $-0.597 \pm 0.033$ ). The female morphs also differed in body shape (significant effect of 239 Morph, Table 3B). Androchromes had significantly more male-like morphology (i.e. longer, 240 narrower abdomen and shorter wings) than Infuscans and Infuscans-obsoleta females $(P<$ 241 0.0001, Figure 2B, LS means \pm SEs: Androchromes: $0.577 \pm 0.029$, Infuscans: $0.887 \pm 0.049$, 242 Infuscans-obsoleta: $0.867 \pm 0.075)$. As with overall size differences, this pattern was constant 243 across populations (no significant effect of Population*Morph, Table 3B) and years (no 244 significant effect of Year*Morph, Table 3B).

246 Conditional independence analysis revealed a unique pattern of phenotypic integration in 247 Infuscans-obsoleta females (Figure 3). Mantel tests demonstrated that all phenotypic 
248 integration (partial correlation) matrices were highly related, with correlation coefficients

249 greater than 0.9 (males vs. Androchromes: $r=0.9798$, males vs. Infuscans: $r=0.9640$, males

250 vs. Infuscans-obsoleta: $\mathrm{r}=0.9192$, Androchromes vs. Infuscans: $\mathrm{r}=0.9825$, Androchromes

251 vs. Infuscans-obsoleta: $\mathrm{r}=0.9306$, and Infuscans vs. Infuscans-obsoleta: $\mathrm{r}=0.9398$; all $P<$

252 0.0001). However, from these correlation coefficients we could see that correlations involving

253 Infuscans-obsoleta were somewhat lower than correlations involving the other two morphs

254 (0.91-0.94 and 0.96-0.99, respectively), and this difference is in fact significant when tested

255 using a t-test $(\mathrm{t}=5.49, \mathrm{df}=4, P=0.005)$. This suggests that phenotypic integration patterns

256 in Androchromes, Infuscans females, and males are all more closely related to each other than

257 any of them are to Infuscans-obsoleta females. In contrast, correlations between the sexes are

258 not lower than correlations within the sexes (i.e. between female morphs; $\mathrm{t}=0.139, \mathrm{df}=4, P$

$259=0.896$ ), so there do not seem to be any large overall differences in phenotypic integration

260 patterns between the sexes. From visual inspection of the phenotypic integration graphs, we

261 can see that Androchromes and Infuscans females had very similar patterns of phenotypic

262 integration, differing only in the strength of some of the partial correlations. Likewise, males

263 had a very similar pattern of phenotypic integration to both Androchromes and Infuscans

264 females, only differing in the addition of a new weak edge between abdomen length and

265 thorax width. In contrast, Infuscans-obsoleta females not only lacked two of the edges present

266 in other females, but also exhibited a unique edge between abdomen width (S4) and total

267 length. This amounts to a $30 \%$ difference in presence/absence of edges ( $3 / 10$ possible edges)

268 between Infuscans-obsoleta and the other two morphs. The high partial correlations between

269 total length and abdomen length seen in all groups are probably because these traits are not

270 completely independent (abdomen length is a component of total length).

271 
272 There was also evidence that morphological differences had morph-specific fitness

273 consequences. Selection gradients on total length, abdomen length, abdomen width, and wing

274 length differed significantly between the morphs (Table 4A). Androchrome females

275 experienced significant positive selection S4 width, Infuscans females experienced significant

276 negative selection on total length but positive selection on abdominal length, and Infuscans-

277 obsoleta females experienced significant positive selection on S4 width but negative selection

278 on wing length (Table 4B).

\section{DISCUSSION}

282 Previous research on laboratory-raised individuals from a single population suggested that the

283 female colour morphs in Ischnura elegans differed in morphology (Abbott \& Svensson,

284 2008). In this study we found that morphological differences observed in the field were

285 generally similar to those previously observed in the laboratory (Abbott \& Svensson, 2008).

286 This study therefore provides clear evidence that the existence of morphological differences

287 between female colour morphs in I. elegans is not simply a laboratory artefact, nor the

288 property of a single population, but is in fact a consistent feature both over time and across all

28912 populations studied here.

291 Sexual size dimorphism is common in damselflies and in non-territorial species such as $I$.

292 elegans females are usually larger than males (Corbet, 1999). Both this fact and previous

293 results (Abbott \& Svensson, 2008) led us to expect to find sexual dimorphism in body size

294 and shape. Indeed, males were smaller than females, with relatively longer, narrower

295 abdomens and shorter wings (Figure 1). Differences in body shape are likely to be related to

296 the positions of the sexes during mating and fecundity selection in females, as discussed in 
297 Abbott \& Svensson (2008). Interestingly, the degree of sexual dimorphism in size and shape

298 varied between populations and years (Tables 2A and 3A). This could be a result of

299 differential sensitivity of the sexes to different abiotic or biotic environmental conditions

300 between populations (Badyaev, 2002). For example, it has previously been found that

301 photoperiod and temperature jointly affect the degree of SSD in the damselfly Lestes viridis

302 (de Block \& Stoks, 2003). Similarly, spatial and temporal fluctuations in the strength of

303 fecundity selection in females or of sexual selection in males (Gosden \& Svensson, 2008)

304 could also produce varying patterns of SSD. Finally, variation in morph frequencies between

305 years/populations in combination with overall size differences between the morphs (see

306 below) could also partly explain spatial and temporal variation in the degree of SSD. Because

307 Infuscans females are larger overall than the other morphs, populations/years with a high

308 frequency of Infuscans females could have higher SSD than populations/years with a low

309 frequency of this morph, assuming male size is more or less constant.

311 Though it has previously been found that Androchromes may be larger than the other morphs

312 in a closely related species (Cordero, 1992), this was not the case in our study populations.

313 Infuscans females were larger than the other morphs, and Androchrome females had

314 relatively longer, narrower abdomens and shorter wings than the other morphs (Figure 2).

315 These consistent morphological differences are particularly striking since they exist despite

316 clinal variation in body size along the coastal-inland gradient in these populations (Gosden \&

317 Svensson, 2008), and stand in sharp contrast to the observed temporal and spatial variation in

318 the degree of sexual dimorphism. Female fecundity is often related to body size in insects

319 (Bonduriansky, 2001), and since previous results (Svensson \& Abbott, 2005) indicate that

320 Infuscans females have higher overall fecundity than the other morphs, it seems reasonable

321 that this elevated fecundity is partially the result of their larger size. However we did not find 
any evidence of selection for larger thorax width, which is the best predictor of overall size

323 (i.e. highest loading on PC1; Table 1), and Infuscans females actually experienced negative

324 selection on total body length (Table 4). This suggests that other selective pressures than

325 fecundity selection may be influencing female size, which is rather surprising given

326 widespread evidence of fecundity selection on size in insects (Bonduriansky, 2001). It is,

327 however, consistent with previous work in two other damselfly species which have found that

328 female size was not related to fecundity (Anholt, 1991; Richardson \& Baker, 1997).

330 The difference in body shape between Androchromes and the other morphs is analogous to

331 the differences between the sexes, though smaller in magnitude (see Results). One common

332 explanation of the maintenance of the polymorphism in this and related species is that

333 Androchrome females are male mimics, and therefore avoid costs of male mating harassment

334 (e.g. Cordero et al., 1998; Cordero Rivera \& Sánchez-Guillén, 2008), and other studies have

335 found evidence of phenotypic similarity of Androchromes to males in colouration and black

336 patterning (Joop et al., 2006; Van Gossum et al., 2008). Although the male mimicry

337 hypothesis only explicitly deals with similarity in colouration between males and

338 Androchrome females, correlated morphological and colour differences in other polymorphic

339 species from a range of taxa (see Introduction) suggest that morphological mimicry could also

340 be a possibility. The more masculine phenotype typical of Androchromes is consistent with

341 this explanation, although other frequency- and density-dependent factors are known to be at

342 work in these populations (Svensson et al., 2005; Gosden \& Svensson, 2007). Some studies

343 suggest that Androchromes are always less preferred by males than other morphs (Hammers

344 \& Van Gossum, 2008; Cordero Rivera \& Sánchez-Guillén, 2008), while others suggest that

345 males learn to recognize and prefer common morphs (Van Gossum et al., 2001a; Van Gossum

346 et al., 2001b; Fincke et al., 2007). Male mimicry and learned mate recognition need not be 
347 mutually exclusive, however, for example if Androchromes must reach higher frequencies

348 than other morphs before males learn to recognize them. Despite evidence of morphological

349 male mimicry in Androchromes, we did not find any clear evidence of selection for

350 masculinized morphology in Androchromes or, alternatively, against masculinized

351 morphology in the other morphs. It is possible that Androchromes are already at or near their

352 morphological optimum and only experience weak stabilizing selection on morphology. It is

353 also possible that our fecundity estimates did not capture aspects of fitness that are subject to

354 selection for masculinization, for example if more masculinized morphology in

355 Androchromes affects survival. However, weak stabilizing selection is unlikely since we

356 found no evidence of stabilizing selection for any trait in Androchromes (data not shown),

357 and there is no evidence of differences in lifespan between morphs in a related polymorphic

358 species (Andrés \& Cordero Rivera, 2001), which speaks against effects of survival selection.

359 This suggests that morphological similarity between males and Androchromes could be the

360 result of pleiotropic effects at the morph locus rather than selection for masculinized

361 morphology. Alternatively, Androchromes could suffer a trade-off between maximising their

362 fecundity and minimising male mating harassment through male mimicry (Gosden and

363 Svensson, submitted) resulting in no net selection for masculinized morphology.

365 Conditional independence analysis (Magwene, 2001) also revealed differing patterns of

366 phenotypic integration between the morphs. Interestingly, rather than seeing a large difference

367 in the pattern of phenotypic integration between the sexes, which is what one might expect

368 based on the existence of sexual dimorphism in size and shape in I. elegans (see above), the

369 largest difference in phenotypic integration was between Infuscans-obsoleta females and the

370 other morphs (Figure 3). This is consistent with laboratory results on morphology (Abbott \&

371 Svensson, 2008) and development time (Abbott \& Svensson, 2005), which also found that 
372 Infuscans-obsoleta females were the most divergent morph. Why this large difference in the

373 pattern of phenotypic integration between Infuscans and Infuscans-obsoleta females does not

374 seem to be reflected in a large difference in PC2 (body shape) is unknown, but could simply

375 be because PC2 is capturing other aspects of shape variation than the phenotypic integration

376 analysis (Jackson, 1991). This is possible since PC2 is likely to be more heavily influenced by

377 differences in shape between the sexes than by differences in shape between the morphs. One

378 of the unique features of the pattern of phenotypic integration in Infuscans-obsoleta was the

379 presence of an edge between abdominal width (S4) and total length. Furthermore, the

380 strongest positive selection gradient in the selection analysis was on S4 width in Infuscans-

381 obsoleta females $(\beta>0.3$, Table 4$)$. It is tempting to speculate that these two results are

382 related, and that strong selection on abdominal width in Infuscans-obsoleta females has

383 resulted in increased phenotypic integration of this trait compared to the other morphs.

384 Similarly, the strongest negative selection gradient in the selection analysis was on wing

385 length in Infuscans-obsoleta females $(\beta<-0.3$, Table 4$)$, and Infuscans-obsoleta is the only

386 group lacking significant integration between abdomen length and wing length. Perhaps

387 strong negative selection on wing length in this morph has resulted in a decoupling of wing

388 length and abdomen length. However why Infuscans-obsoleta females experience such strong

389 selection on these particular traits is currently unknown. More research on differing patterns

390 of phenotypic and genetic integration of traits between the morphs is obviously needed if a

391 detailed understanding of their evolution is to be achieved.

393 If fecundity selection for increased size or for morphological male mimicry in Androchromes

394 cannot explain the morph-specific patterns of selection on morphology seen here, another

395 possibility could be that each morph is selected to be better adapted to slightly different

396 ecological conditions. Morph frequencies in this species differ both between geographical 
regions in Europe (Gosden, 2008) and between newly-established and older populations

398 within southern Sweden (Svensson \& Abbott, 2005), suggesting a role for ecological

399 specialization and local adaptation in determining morph frequencies. Note that ecological

400 differences between the morphs and the existence of negative frequency-dependence are not

401 mutually exclusive. Ecological differences between the morphs could determine the range of

402 morph frequencies that are stable in different populations or regions, while frequency-

403 dependence could regulate morph frequency dynamics within that range (Andrés et al., 2000;

404 Abbott et al., 2008). For example, ecological determination of stable ranges of morph

405 frequencies have been found in the candy-strip spider Enoplagnatha ovata (Oxford, 2005).

406 The existence of ecological differences between the morphs and their interaction with other

407 factors is a potentially productive area for future research.

409 We have previously argued that the female morphs in I. elegans may be pursuing alternative

410 phenotypically integrated strategies (Abbott \& Svensson, 2008). The existence of correlated

411 differences in morphological (this study), behavioural (Van Gossum et al., 2001a; Gosden \&

412 Svensson, 2007), and life history traits (Abbott \& Svensson, 2005; Svensson \& Abbott, 2005)

413 between morphs of I. elegans in our study populations support this idea, as does recent

414 research showing differential effects of male mating harassment on the morphs (Gosden and

415 Svensson, submitted). Although more research is needed before full knowledge of the nature

416 of these strategies is achieved, this system has the potential to become a model system for the

417 evolution of alternative female sexual polymorphisms (Svensson et al., in press).

419 ACKNOWLEDGEMENTS 
421 We thank Anne Kidd and especially Erik Svensson for comments and discussions on earlier

422 versions of this manuscript. We also thank two anonymous referees for helpful comments and 423 suggestions. Financial support for this study was provided by Oscar and Lili Lamms Stiftelse 424 and the Swedish Research Council (Vetenskapsrådet) to Erik Svensson.

\section{REFERENCES}

429 Abbott, J. and Svensson, E. I. 2005. Phenotypic and genetic variation in emergence and development time of a trimorphic damselfly. Journal of Evolutionary Biology 18: 1464-1470.

432 Abbott, J. K. 2006. Ontogeny and population biology of a sex-limited colour polymorphism.

$433 \mathrm{PhD}$ thesis. Lund University .

434 Abbott, J. K., Bensch, S., Gosden, T. P., and Svensson, E. I. 2008. Patterns of differentiation

435 in a colour polymorphism and in neutral markers reveal rapid genetic changes in natural 436 damselfly populations. Molecular Ecology 17: 1597-1604.

438 Abbott, J. K. and Svensson, E. I. 2008. Differential breakdown of intersexual genetic 439 correlations in an intraspecific mimicry system. Submitted.

440 Abbott, J. K. and Svensson, E. I. 2008. Ontogeny of sexual dimorphism and phenotypic 441 integration in heritable morphs. Evolutionary Ecology 22: 103-121. 
443 Ahnesjö, J. and Forsman, A. 2003. Correlated evolution of colour pattern and body size in

444 polymorphic pygmy grasshoppers, Tetrix undulata. Journal of Evolutionary Biology 16:

$445 \quad 1308-1318$.

446

447 Ahnesjö, J. and Forsman, A. 2006. Differential habitat selection by pygmy grasshopper color

448 morphs; interactive effects of temperature and predator avoidance. Evolutionary Ecology 20:

$449235-257$.

450

451 Andrés, J. A. and Cordero Rivera, A. 2001. Survival rates in a natural population of the

452 damselfly Ceriagrion tenellum: effects of sex and female phenotype. Ecological Entomology

453 26: 341-346.

454

455 Andrés, J. A., Sánchez-Guillén, R. A., and Cordero Rivera, A. 2000. Molecular evidence for

456 selection on female colour polymorphism in the damselfly Ischnura graellsii. Evolution 54:

$457 \quad 2156-2161$.

459 Anholt, B. R. 1991. Measuring selection on a population of damselflies with a manipulated

460 phenotype. Evolution 45: 1091-1106.

461

462 Askew, R. R. 1988. The dragonflies of Europe. Harley Books, Colchester, Essex.

463 Badyaev, A. V. 2002. Growing apart: an ontogenetic perspective on the evolution of sexual

464 size dimorphism. Trends in Ecology and Evolution 17: 369-378. 
466 Banks, M. J. and Thompson, D. J. 1987. Lifetime reproductive success of females of the

467 damselfly Coenagrion puella. Journal of Animal Ecology 56: 815-832.

468

469 Bonduriansky, R. 2001. The evolution of male mate choice in insects: a synthesis of ideas and 470 evidence. Biological Reviews 76: 305-339.

471

472 Corbet, P. S. 1999. Dragonflies: behaviour and ecology of Odonata. Harley Books,

473 Colchester, Essex.

474 Cordero Rivera, A. and Sánchez-Guillén, R. A. 2008. Male-like females of a damselfly are 475 not preferred by males even if they are the majority morph. Animal Behaviour 74: 247-252.

477 Cordero, A. 1990. The inheritance of female polymorphism in the damselfly Ischnura

478 graellsii (Rambur) (Odonata: Coenagrionidae). Heredity 64: 341-346.

480 Cordero, A. 1992. Density-dependent mating success and colour polymorphism in females of 481 the damselfly Ischnura graellsii (Odonata: Coenagrionidae). Journal of Animal Ecology 61: $482 \quad 769-780$.

484 Cordero, A., Santolamazza Carbone, S., and Utzeri, C. 1998. Mating opportunities and mating 485 costs are reduced in androchrome female damselflies, Ischnura elegans (Odonata). Animal 486 Behaviour 55: 185-197. 
488 de Block, M. and Stoks, R. 2003. Adaptive sex-specific life history plasticity to temperature

489 and photoperiod in a damselfly. Journal of Evolutionary Biology 16: 986-995.

490

491 Eroukhmanoff, F. and Svensson, E. I. 2008. Phenotypic integration and conserved covariance

492 structure in calopterygid damselflies. Journal of Evolutionary Biology 21: 514-526.

493

494 Fincke, O. M. 1986. Lifetime reproductive success and the opportunity for selection in a 495 nonterritorial damselfly (Odonata, Coenagrionidae). Evolution 40: 791-803.

497 Fincke, O. M., Fargevieille, A., and Schultz, T. D. 2007. Lack of innate preference for morph 498 and species identity in mate-searching Enallagma damselflies. Behavioural Ecology and 499 Sociobiology 61: 1121-1131.

501 Galeotti, P., Rubolini, D., Dunn, P. O., and Fasola, M. 2003. Colour polymorphism in birds:

502 causes and functions. Journal of Evolutionary Biology 16: 635-646.

504 Gosden, T. 2008. The preservation of favoured morphs in the struggle between sexes. $\mathrm{PhD}$ 505 thesis. Lund University.

506 Gosden, T. P. and Svensson, E. I. 2007. Female sexual polymorphism and fecundity

507 consequences of male mating harassment in the wild. PLoS One 2: e580. 
509 Gosden, T. P. and Svensson, E. I. 2008. Density-dependent male mating harassment, female

510 resistance and male mimicry. Submitted.

511 Gosden, T. P. and Svensson, E. I. 2008. Spatial and temporal dynamics in a sexual selection

512 mosaic. Evolution 62: 845-856.

513

514 Gray, S. M. and McKinnon, J. S. 2007. Linking color polymorphism maintenance and

515 speciation. Trends in Ecology and Evolution 22: 71-79.

516

517 Hammers, M. and Van Gossum, H. 2008. Variation in female morph frequencies and mating

518 frequencies: random, frequency-dependent harassment or male mimicry? Animal Behaviour

519 76: 1403-1410.

520

521 Hinnekint, B. O. N. 1987. Population dynamics of Ischnura e. elegans (Vander Linden)

522 (Insecta: Odonata) with special reference to morphological colour changes, female

523 polymorphism, multiannual cycles and their influence on behaviour. Hydrobiologia 146: 3-

52431.

525

526 Jackson, J. E. 1991. A user's guide to principal components. John Wiley \& Sons, Inc., New

527 York.

528 Joop, G., Siva-Jothy, M. T., and Rolff, J. 2006. Female colour polymorphism: gender and the 529 eye of the beholder in damselflies. Evolutionary Ecology 20: 259-270. 
531 Lande, R. and Arnold, S. J. 1983. The measurement of selection on correlated characters.

532 Evolution 37: 1210-1226.

533

534 Leimar, O. 2005. The evolution of phenotypic polymorphism: randomized strategies versus

535 evolutionary branching. The American Naturalist 165: 669-681.

536

537 Magwene, P. M. 2001. New tools for studying integration and modularity. Evolution 55:

$538 \quad 1734-1745$.

539

540 Mills, S. C., Hazard, L., Lancaster, L., Mappes, T., Miles, D., Oksanen, T. A., and Sinervo, B.

541 2008. Gonadotropin hormone modulation of testosterone, immune function, performance, and

542 behavioural trade-offs among male morphs of the lizard Uta stansburiana. The American

543 Naturalist 171: 339-357.

545 Nosil, P., Crespi, B. J., and Sandoval, C. P. 2003. Reproductive isolation driven by the

546 combined effects of ecological adaptation and reinforcement. Proceedings of the Royal

547 Society of London B 270: 1911-1918.

548

549 Oxford, G. S. 2005. Genetic drift within a protected polymorphism: enigmatic variation in

550 color-morph frequencies in the candy-stripe spider, Enoplognatha ovata. Evolution 59: 2170-

5512184. 
553 Richardson, J. M. L. and Baker, R. L. 1997. Effect of body size and feeding on fecundity in

554 the damselfly Ischnura verticalis (Odonata: Coenagriondae). Oikos 79: 477-483.

556 Robertson, H. M. 1985. Female dimorphism and mating behaviour in a damselfly, Ischnura

557 ramburi: females mimicking males. Animal Behaviour 33: 805-809.

559 Sánchez-Guillén, R. A., Van Gossum, H., and Cordero Rivera, A. 2005. Hybridization and

560 the inheritance of female colour polymorphism in two Ischnurid damselflies (Odonata:

561 Coenagrionidae). Biological Journal of the Linnean Society 85: 471-481.

562

563 Schluter, D. 2000. The ecology of adaptive radiation. Oxford University Press, Oxford.

564 Statsoft, Inc. STATISTICA (data analysis software). [7]. 2004. Tulsa, OK.

565 Svensson, E., Sinervo, B., and Comendant, T. 2001. Density dependent competition and

566 selection on immune function in genetic lizard morphs. Proceedings of the National Academy

567 of Sciences, USA 98: 12561-12565.

569 Svensson, E. I. and Abbott, J. 2005. Evolutionary dynamics and population biology of a 570 polymorphic insect. Journal of Evolutionary Biology 18: 1503-1514.

572 Svensson, E. I., Abbott, J., and Härdling, R. 2005. Female polymorphism, frequency-

573 dependence and rapid evolutionary dynamics in natural populations. The American Naturalist

574 165: 567-576. 
576 Svensson, E. I., Abbott, J. K., Gosden, T. P., and Coreau, A. 2008. Female polymorphisms,

577 sexual conflict and limits to speciation processes in animals. Evolutionary Ecology In press.

$578 \quad 10.1007 / \mathrm{s} 10682-007-9208-2$

579 Van Gossum, H., Robb, T., Forbes, M. R., and Rasmussen, L. 2008. Female-limited

580 polymorphism in a widespread damselfly: morph frequencies, male density, and phenotypic

581 similarity of andromorphs to males. Canadian Journal of Zoology 86: 1131-1138.

582

583 Van Gossum, H., Stoks, R., and De Bruyn, L. 2001a. Frequency-dependent male mate

584 harassment and intra-specific variation in its avoidance by females of the damselfly Ischnura 585 elegans. Behavioural Ecology and Sociobiology 51: 69-75.

586

587 Van Gossum, H., Stoks, R., and De Bruyn, L. 2001b. Reversible frequency-dependent 588 switches in male mate choice. Proceedings of the Royal Society of London B 268: 83-85.

590 Vines, T. H. and Schluter, D. 2006. Strong assortative mating between allopatric sticklebacks 591 as a by-product of adaptation to different environments. Proceedings of the Royal Society of 592 London B 273: 911-916. 
Table 1: Factor loadings for the first and second principal components calculated from five morphological traits. PC1 is a measure of overall size and accounted for $63.98 \%$ of the total variation in morphology between individuals. PC2 is a measure of body shape, where individuals with positive values of PC2 have longer wings and wider but shorter abdomens, and accounted for $21.44 \%$ of the total variation in morphology between individuals.

$\begin{array}{lll}\text { Measurement } & \text { Loading PC1 Loding PC2 }\end{array}$

Total length

0.8234

$-0.4916$

Abdomen length

0.7930

$-0.5397$

Thorax width

0.8449

0.0925

S4 width

0.7086

0.6181

Wing length

0.8224

0.3850 
Table 2: Results of statistical analysis of body size (PC1) using mixed models. Population and Year are random effects, as are all interactions with Population and Year. Sex and Morph are fixed effects, and were included in separate analyses (see Methods). $\mathrm{N}=4937$ (all individuals) for Sex (A), and $\mathrm{N}=2196$ (females only) for Morph (B).

Effect

Df

MS

F

$P$-value

A)

$\begin{array}{llccc}\text { Population } & 11 & 46.18 & 20.14 & <0.0001 \\ \text { Sex } & 1 & 570.8 & 423.9 & <0.0001 \\ \text { Year } & 3 & 36.99 & 19.40 & 0.0001 \\ \text { Population*Sex } & 11 & 1.200 & 2.832 & 0.0011 \\ \text { Population*Year } & 33 & 2.108 & 4.975 & <0.0001 \\ \text { Sex*Year } & 3 & 2.004 & 4.730 & 0.0027 \\ \text { Error } & 4874 & 0.424 & & \end{array}$

B)

$\begin{array}{lllll}\text { Population } & 11 & 20.49 & 24.21 & <0.0001 \\ \text { Morph } & 2 & 1.221 & 3.116 & 0.0768 \\ \text { Year } & 3 & 11.92 & 17.04 & <0.0001 \\ \text { Population*Morph } & 22 & 0.448 & 0.990 & 0.4733 \\ \text { Population*Year } & 33 & 1.393 & 3.077 & <0.0001 \\ \text { Morph*Year } & 6 & 0.359 & 0.792 & 0.5761 \\ \text { Error } & 2118 & 0.453 & & \end{array}$


Table 3: Results of statistical analysis of body shape (PC2) using mixed models. Population and Year are random effects, as are all interactions with Population and Year. Sex and Morph are fixed effects, and were included in separate analyses (see Methods). $\mathrm{N}=4937$ (all individuals) for Sex (A), and $\mathrm{N}=2196$ (females only) for Morph (B).

Effect

Df

MS

F

$P$-value

A)

$\begin{array}{llccc}\text { Population } & 11 & 14.95 & 8.946 & <0.0001 \\ \text { Sex } & 1 & 596.6 & 860.7 & <0.0001 \\ \text { Year } & 3 & 13.29 & 15.57 & <0.0001 \\ \text { Population*Sex } & 11 & 1.131 & 2.310 & 0.0081 \\ \text { Population*Year } & 33 & 1.407 & 2.873 & <0.0001 \\ \text { Sex*Year } & 3 & 0.432 & 0.882 & 0.4498 \\ \text { Error } & 4874 & 0.490 & & \end{array}$

B)

$\begin{array}{lllll}\text { Population } & 11 & 4.971 & 6.676 & <0.0001 \\ \text { Morph } & 2 & 11.89 & 16.09 & 0.0005 \\ \text { Year } & 3 & 13.21 & 16.71 & <0.0001 \\ \text { Population*Morph } & 22 & 0.572 & 1.106 & 0.3318 \\ \text { Population*Year } & 33 & 0.986 & 1.906 & 0.0015 \\ \text { Morph*Year } & 6 & 0.824 & 1.594 & 0.1449 \\ \text { Error } & 2118 & 0.517 & & \end{array}$


Table 4: Summary of results of selection gradient analysis for five morphological traits (significant values are highlighted in bold). A) Results of analysis to identify traits with morph-specific variation in the magnitude and/or direction of selection. There was evidence of variation in overall fecundity levels between years and populations, and of overall positive selection on S4 width and wing length. However, all traits except thorax width also showed evidence of morph-specific effects on the magnitude and/or direction of selection. B) Morph-specific selection gradients for all five morphological traits (SEs reported in brackets) calculated from separate analyses for each morph (see Methods). Androchrome females experienced significant positive selection on S4 width, Infuscans females experienced significant negative selection on total length but positive selection on abdominal length, and Infuscans-obsoleta females experienced significant positive selection on S4 width but negative selection on wing length.

A)

$\begin{array}{lllll}\text { Effect } & \text { Df } & \text { MS } & \text { F } & P \text {-value } \\ \text { Population } & 11 & 1.864 & 1.692 & 0.1116 \\ \text { Year } & 3 & 2.943 & 3.323 & \mathbf{0 . 0 2 5 1} \\ \text { Year*Population } & 32 & 1.249 & 2.380 & <\mathbf{0 . 0 0 0 1} \\ \text { Total length } & 1 & 0.051 & 0.096 & 0.7563 \\ \text { Abdomen length } & 1 & 0.352 & 0.671 & 0.4130\end{array}$




\begin{tabular}{|c|c|c|c|c|}
\hline Thorax width & 1 & 0.004 & 0.007 & 0.9328 \\
\hline S4 width & 1 & 8.885 & 16.94 & $<0.0001$ \\
\hline Wing length & 1 & 2.915 & 5.556 & 0.0185 \\
\hline Total length*Morph & 2 & 1.623 & 3.093 & 0.0457 \\
\hline Abdomen length*Morph & 2 & 1.943 & 3.703 & 0.0249 \\
\hline Thorax width*Morph & 2 & 0.050 & 0.094 & 0.9100 \\
\hline S4 width*Morph & 2 & 3.490 & 6.653 & 0.0013 \\
\hline Wing length*Morph & 2 & 1.999 & 3.810 & 0.0224 \\
\hline Error & 1535 & 0.525 & & \\
\hline \multicolumn{5}{|l|}{ B) } \\
\hline Trait & Androchrome & \multicolumn{2}{|c|}{ Infuscans } & Infuscans-obsoleta \\
\hline Total length & $0.0838(0.0476)$ & \multicolumn{2}{|c|}{$-0.1576(0.0761)$} & $0.0478(0.3467)$ \\
\hline Abdomen length & $-0.0521(0.0514)$ & \multicolumn{2}{|c|}{$0.1680(0.0710)$} & $0.1659(0.3319)$ \\
\hline Thorax width & $-0.0003(0.0371)$ & \multicolumn{2}{|c|}{$0.0109(0.0500)$} & $-0.0646(0.1427)$ \\
\hline S4 width & $0.0918(0.0306)$ & \multicolumn{2}{|c|}{$-0.0023(0.0411)$} & $0.3620(0.1404)$ \\
\hline
\end{tabular}


Figure 1: Sexual dimorphism in body size (PC1) according to A) population, and $\mathrm{B}$ ) year, and sexual dimorphism in C) body shape (PC2) according to population. Population abbreviations are as follows: $\mathrm{F} 1=$ Flyinge 30A1, F3 = Flyinge 30A3, Ge $=$ Genarp, Gu = Gunnesbo, Ha = Habo, Hof = Hofterupssjön, H14 = Höje å 14, H6 = Höje å 6, H7 = Höje å 7, L = Lomma, $\mathrm{VM}=$ Vallby mosse, and $\mathrm{Vo}_{\mathrm{o}}=$ Vombs vattenerk. Females are always significantly larger than males, but the degree of sexual size dimorphism varied between populations and years. Similarly, males have relatively longer, narrower abdomens and shorter wings than females (lower values of PC2) but the magnitude of differences in body shape between the sexes varied between populations. Error bars denote SEs. Note that cartoon damselflies are for illustrative purposes only and do not reflect the magnitude of actual differences between the sexes.

Figure 2: Differences in between the morphs in A) Body size (PC1). Infuscans females are the largest overall. B) Body shape (PC2). Androchromes are most male-like in shape, while Infuscans and Infuscans-obsoleta females are less male-like and very similar in shape. Error bars denote SEs. Note that cartoon damselflies are for illustrative purposes only and do not reflect the magnitude of actual differences between the morphs.

Figure 3: Phenotypic integration graphs for A) Males ( $=2741$ individuals), $B)$ Androchrome females ( $\mathrm{N}=1457$ individuals), $C)$ Infuscans females ( $\mathrm{N}=564$ individuals $)$, and D) Infuscans-obsoleta females $(\mathrm{N}=176$ individuals). Partial correlations which are significant at the 0.05 level are shown, and values are reported adjacent to lines between traits. Strong edges are indicated by heavy lines, weak edges by light lines. The high partial correlations between total length and abdomen length present in all groups are because these 
traits are not completely independent. Note the unique pattern of phenotypic integration in Infuscans-obsoleta females. 


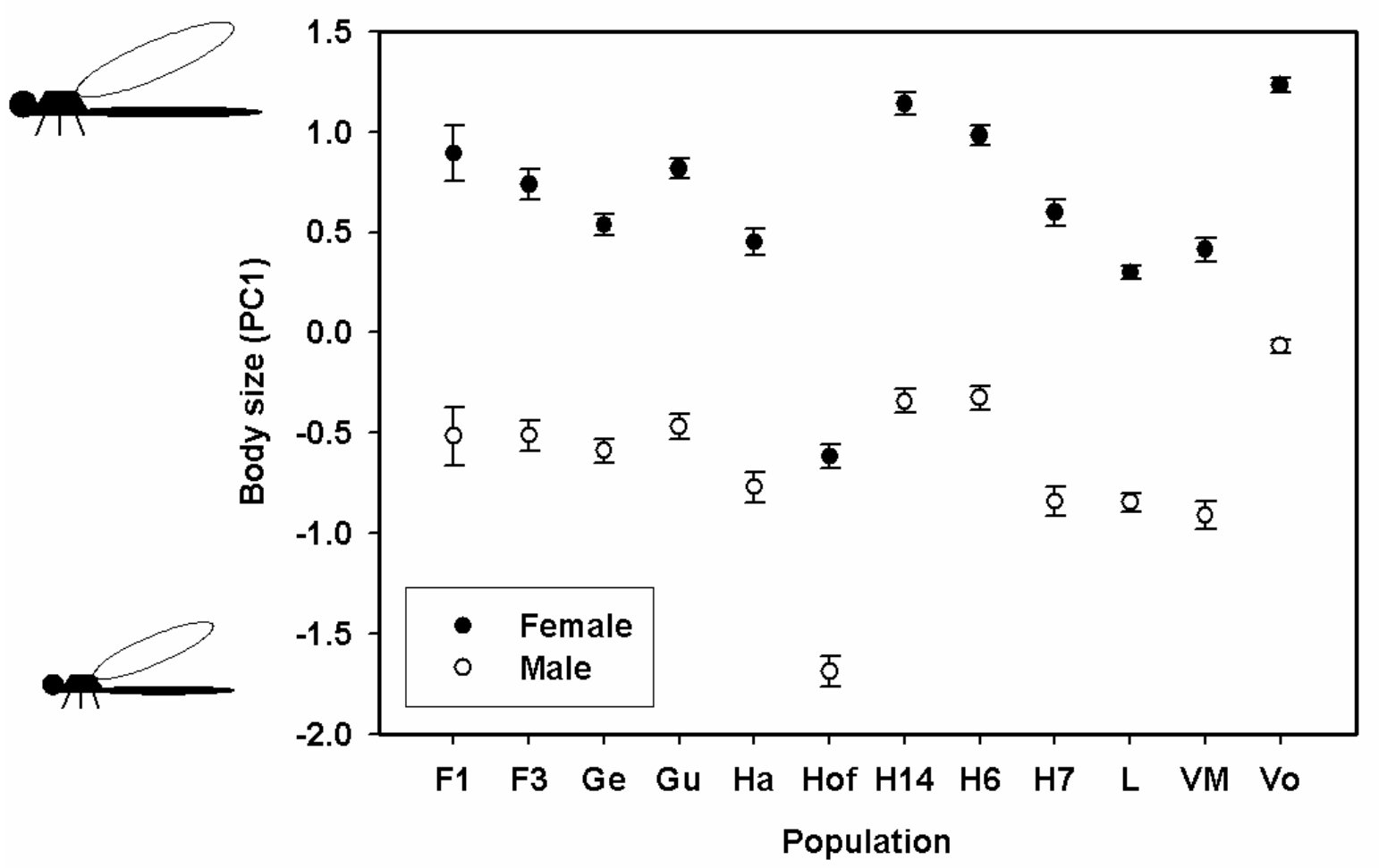

596 Figure 1A 


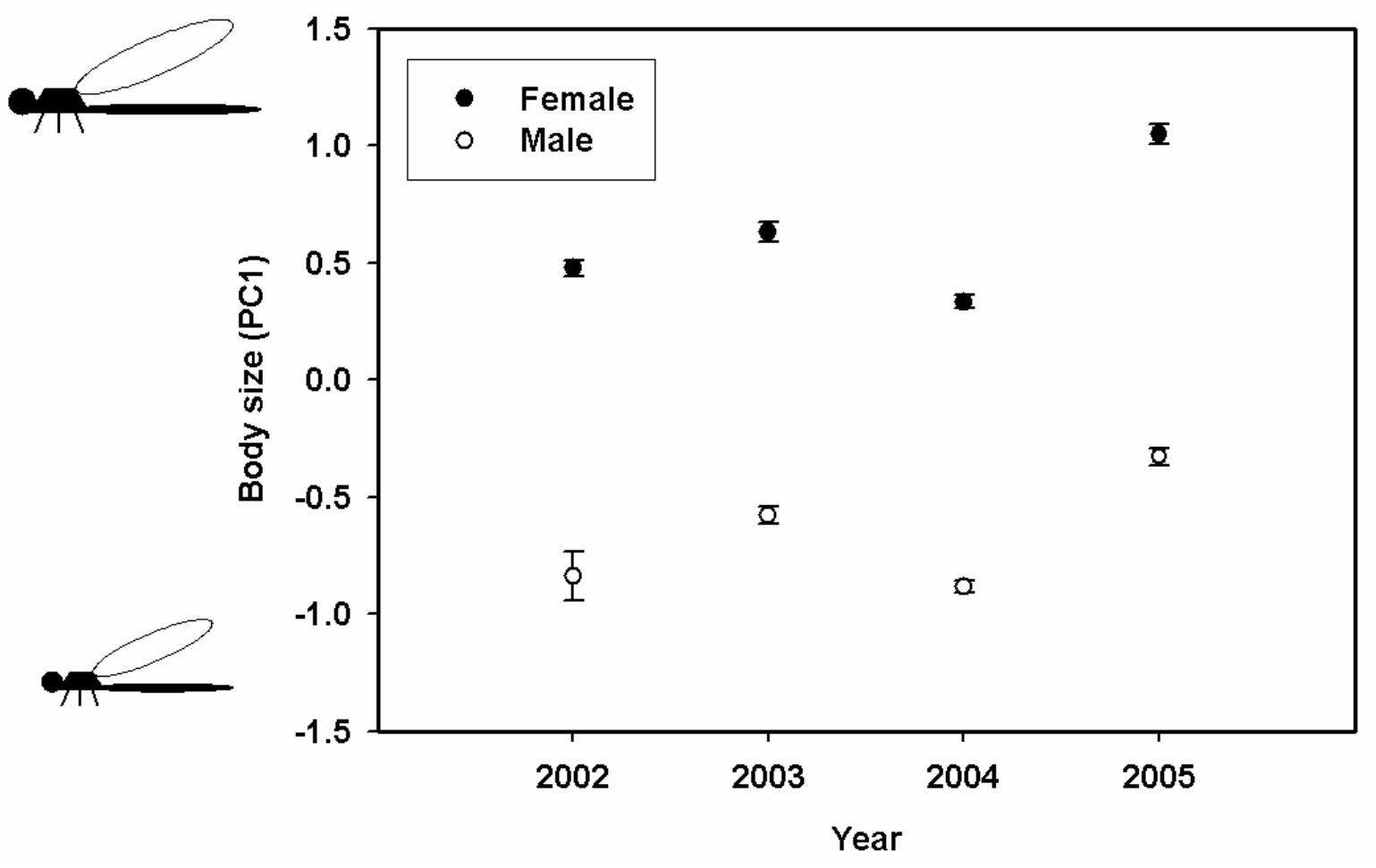

598 Figure 1B 


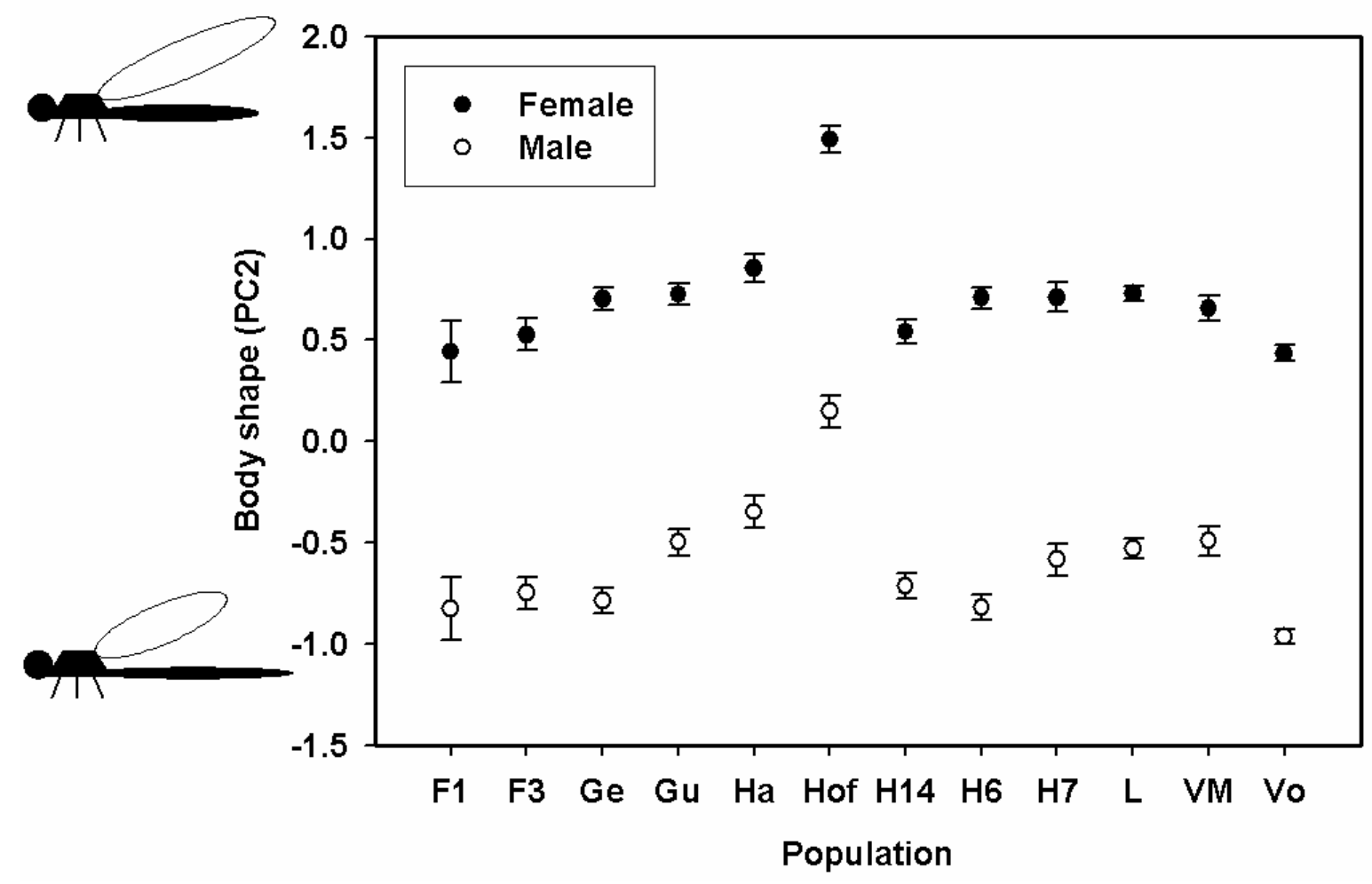

600 Figure 1C 


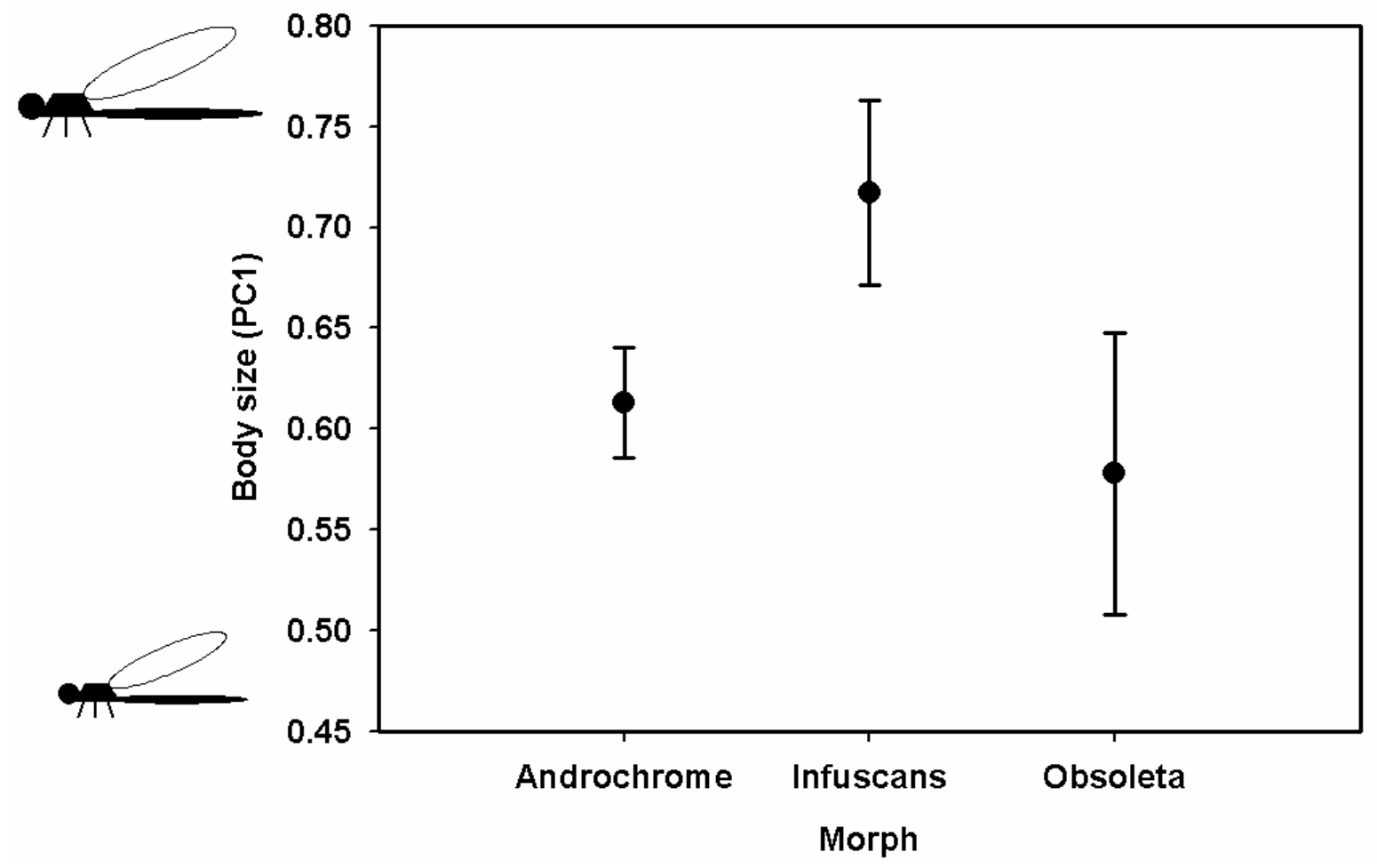

601

602 Figure 2A 


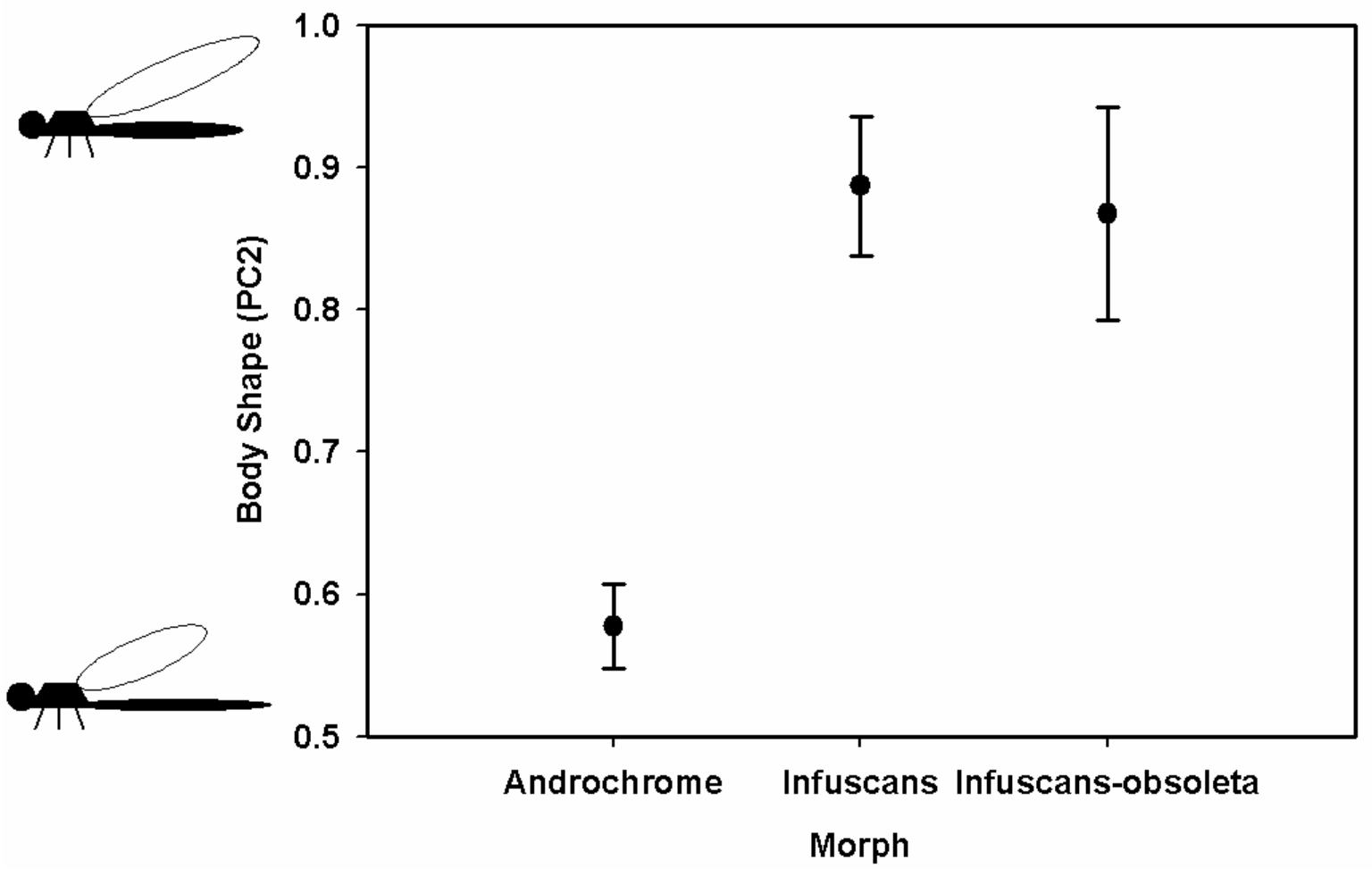

603

604 Figure 2B 


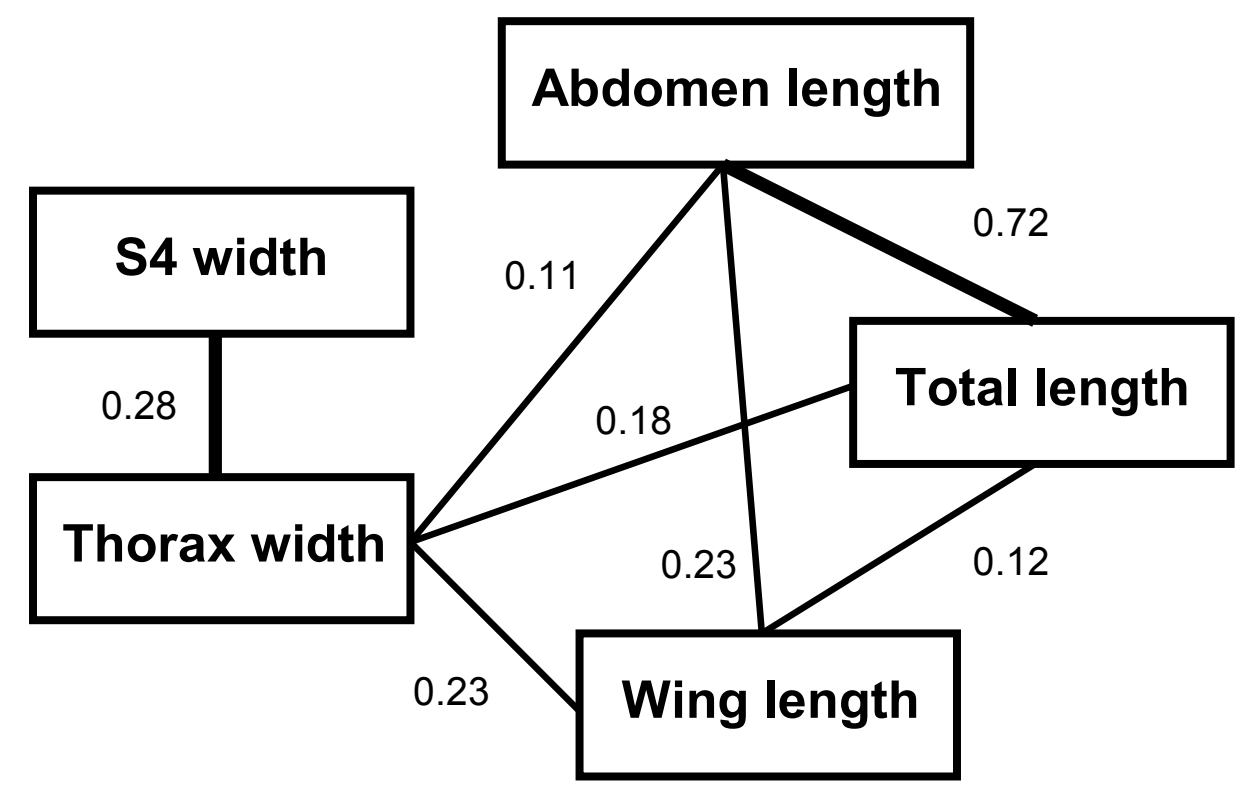

\section{Males}

605

606 Figure 3A 


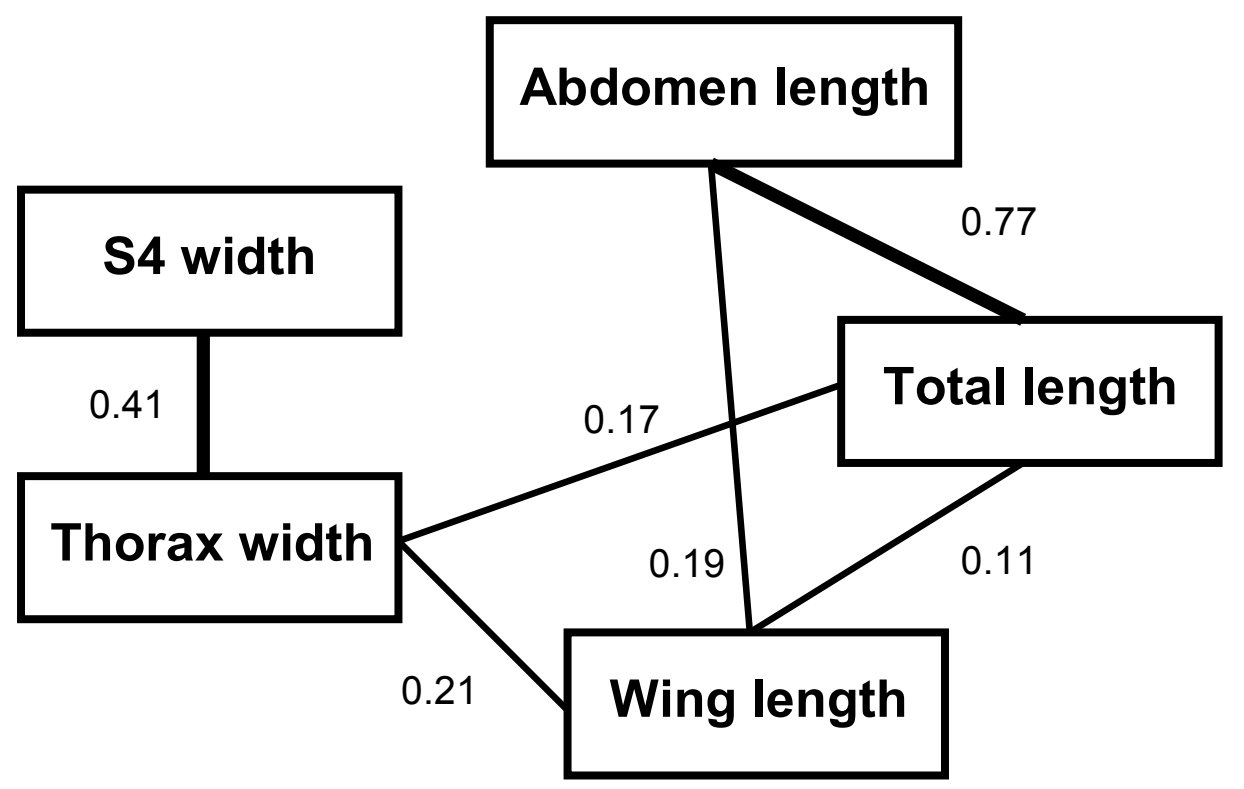

\section{Androchrome}

607

608 Figure 3B 


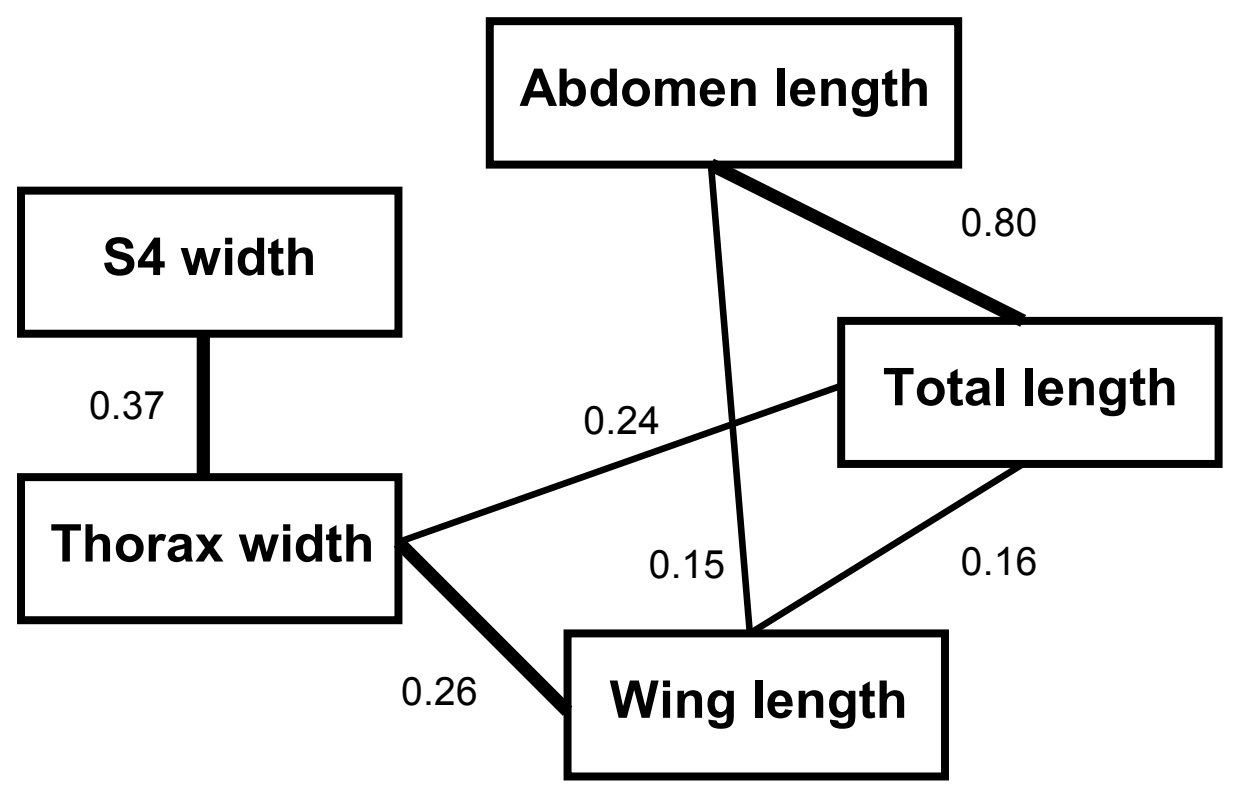

Infuscans

609

610 Figure 3C 


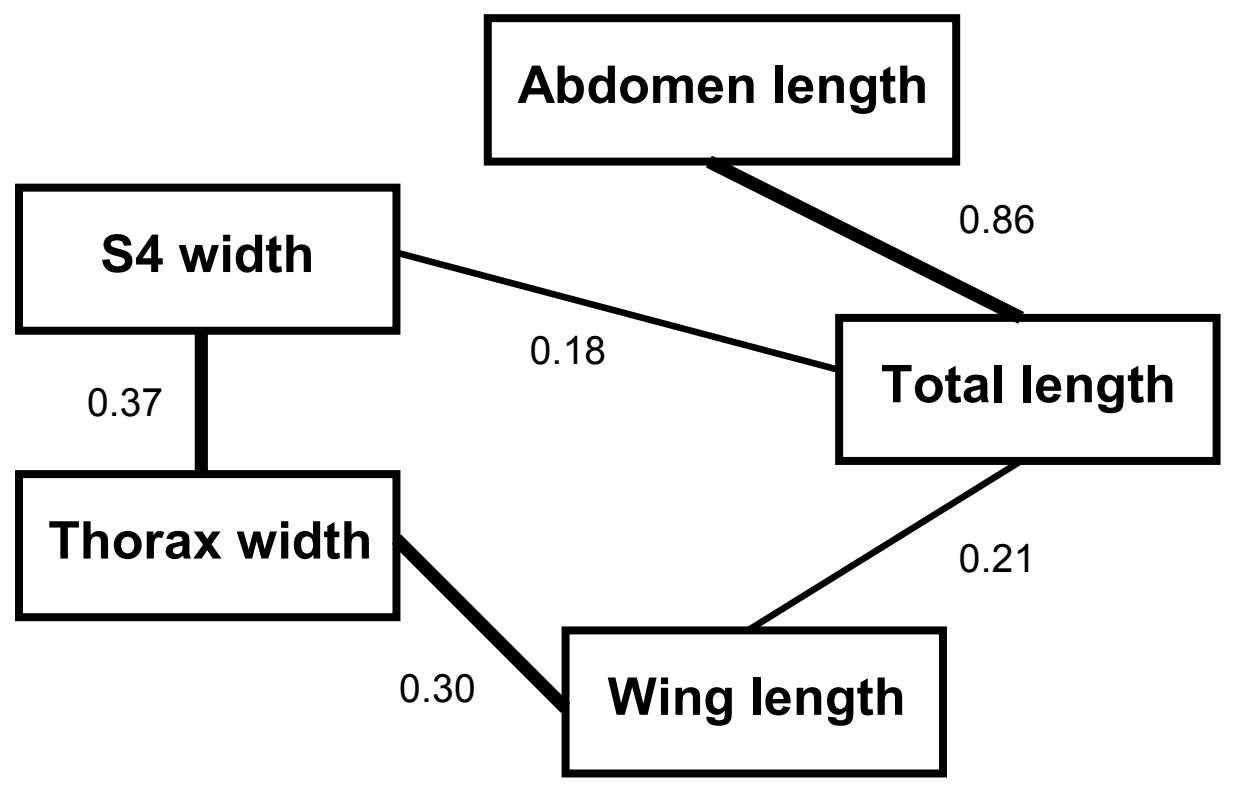

Infuscans-obsoleta

611

612 Figure 3D

613

614

615

616

617 